\title{
On a method to employ Newton's Rings concept to determine thickness of thin films
}

\author{
K. H. Raveesha ${ }^{1, \star}$, Vijaykumar H. Doddamani ${ }^{2, \star \star}$, B. K. Prasad ${ }^{1, \star \star \star}$ \\ ${ }^{1}$ Deparment of Physics, CMR Institute of Technology, Bangalore, India \\ ${ }^{2}$ Department of Physics, Bangalore University, Bangalore, India \\ *-***E-mail address: hod.physics@cmrit.ac.in , drvhdmani@gmail.com , \\ Prasad.bk@cmrit.ac.in
}

\begin{abstract}
Newton's Rings experiment is traditionally utilized to find radius curvature of a lens. We propose a method in which this same set up can be used to find the thickness of thin films. The working principle is interference. It is based on the fact that, the formation of bright and dark interference fringes is a measure of the thickness of the air film at that point. We present the experimental data. The results from the experiment are in agreement with results obtained through geometry. Further, a method to improvise conventional interference at air wedge experiment which is generally used to determine the thickness of thin films is suggested.
\end{abstract}

Keywords: Interference; fringes; destructive interference; constructive interference; air wedge

\section{INTRODUCTION}

It is well known Newton described the formation of bright and dark rings using the plano convex lens. It is understood that when a monochromatic beam of light falls normally on a Plano-convex lens kept on an optically plane glass plate, concentric bright and dark circular fringes are formed due to the constructive and destructive interference of light waves reflected from the lower surface of the lens and the upper surface of the plane glass plate. Formation of a bright or dark fringe at a point depends on the thickness of the air film at that point (which creates path difference). Conventionally Newton's rings experiment is used to determine the radius of curvature of a plano convex lens. We have described a method to utilize the same set up to find the thickness of thin films. In next section, the method is explained in detail. In section 2, data analysis is provided and thickness of few sample paper strips is determined. In Section 3, using a geometrical method we have shown the correctness of our result. The result obtained by the geometrical method is of the same order as what is obtained in the experiment. In section 4, we use this principle to show how the conventional method of Interference at air wedge can be improvised to find the thickness of thin films in a easier way. Conclusions are summarized in the last section 5 [1-15]. 


\section{METHOD}

The thin film whose thickness is to be determined is inserted carefully between the Plano convex lens and the plane glass plate as shown in the figure. If the thin film stops moving any further it implies that the thickness of film just matches the thickness of air gap at the contact point. At this position, observing though the microscope, the exact fringe number (bright or dark) next to the thin film is to be counted. Figure 1 shows a case where the film has a thickness equivalent to the air gap, $\left(t_{6}\right)_{D}$ at point $\mathrm{A}$ (below $6^{\text {th }}$ dark ring).

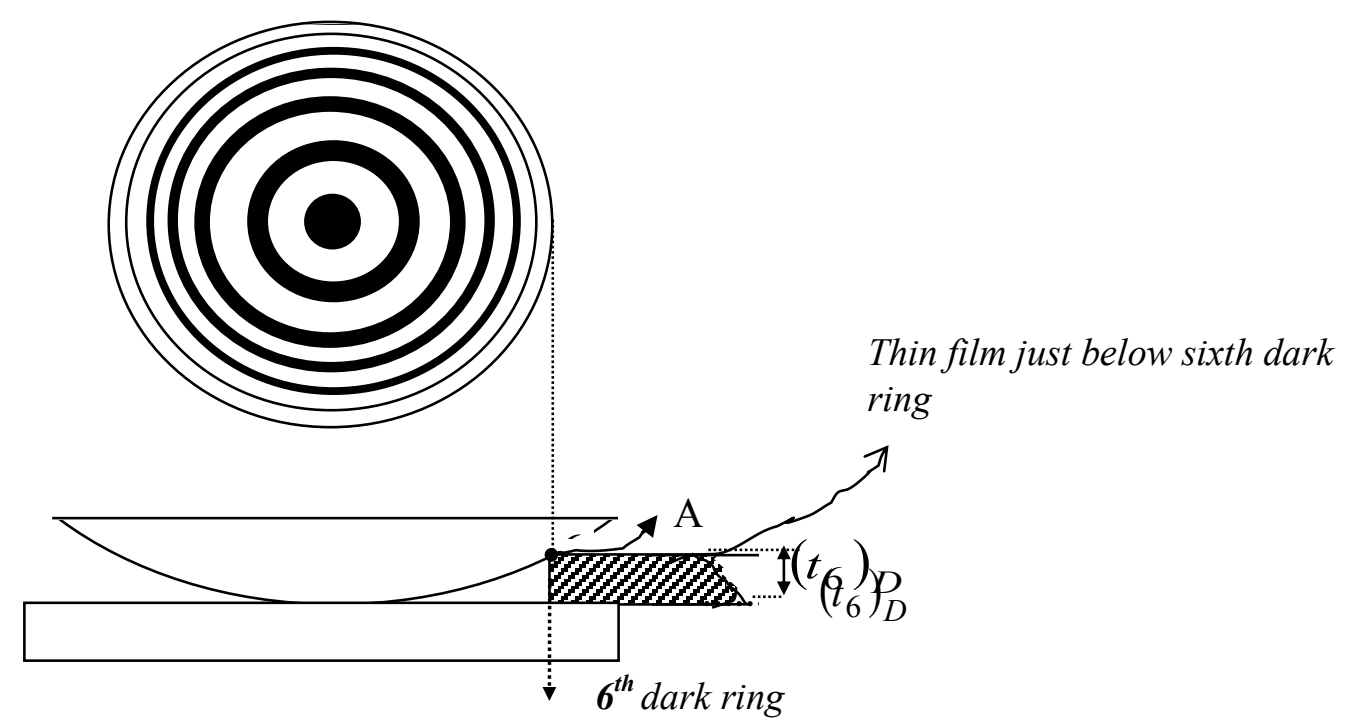

Figure 1. A thin paper strip which has moved till $6^{\text {th }}$ dark fringe. Thickness of the air film below $6^{\text {th }}$ dark ring $\left(t_{6}\right)_{D}$ is equivalent to the thickness of the thin film inserted (when it just touches the lens below the $6^{\text {th }}$ dark fringe at A).

From the equation for destructive interference, $2 t+\frac{\lambda}{2}=(2 n+1) \frac{\lambda}{2}$, using a sodium source of wavelength $\lambda=5893 \AA$ and knowing $n=6$, the thickness of the air gap under the $6^{\text {th }}$ dark fringe or the thickness of the thin film $=1.7679 \times 10^{-6} \mathrm{~m}$.

\section{Section 1: Data analysis}

We used this method to find the thickness of a carbon strip and an ordinary paper strip. The data obtained are shown below. We need to ensure that the paper strip is inserted very carefully. Otherwise the fringes get disturbed. As the fringe number increases, the fringes come closer and closer and it becomes difficult to count the fringes and also to identify the exact type of fringe (whether bright or dark). However a $10 \%$ error in counting the fringes alters the final value by 2 micro metres which is tolerable.

\section{For a carbon paper strip:}

With sodium Lamp source $(\lambda=5893 \AA)$, when a thin carbon paper strip is inserted gently, it moved till $194^{\text {th }}$ dark fringe. 
The Equation for destructive interference is $2 t+\frac{\lambda}{2}=(2 n+1) \frac{\lambda}{2}$

Here $\mathrm{n}=194$

$\lambda=5893 \AA$

On Substitution

$2 \mathrm{t}=(2 n+1) \frac{\lambda}{2}-\frac{\lambda}{2}=2 n \frac{\lambda}{2}=2 \times 194 \times 5893 \times 10^{-10} \times \frac{1}{2}=114 \times 10^{-6} \mathrm{~m}=114 \mu \mathrm{m}$

$\mathrm{t}=57 \mu \mathrm{m}$

\section{For an ordinary paper strip:}

With sodium Lamp source $(\lambda=5893 \AA)$, when an ordinary paper strip is was inserted gently, it moved till $226^{\text {th }}$ dark fringe.

The Equation for destructive interference is $2 t+\frac{\lambda}{2}=(2 n+1) \frac{\lambda}{2}$

Here $\mathrm{n}=226$

$\lambda=5893 \AA$

on Substitution

$2 \mathrm{t}=(2 n+1) \frac{\lambda}{2}-\frac{\lambda}{2}=2 n \frac{\lambda}{2}=2 \times 226 \times 5893 \times 10^{-10} \times \frac{1}{2}=133 \times 10^{-6} \mathrm{~m}=133 \mu \mathrm{m}$

$\mathrm{t}=66.3 \mu \mathrm{m}$

\section{Section 2: Geometrical method to check the correctness of the proposed method}

We present here the discussion on the correctness of this method confirmed through geometry as shown in Fig 2.

With a travelling microscope, the distance of the $6^{\text {th }}$ dark fringe from the centre $\mathrm{O}$ is measure as $0.155 \mathrm{~cm}$.

From the triangle $\mathrm{ABC}$ :

$$
\begin{aligned}
& (\mathrm{AB})^{2}+(\mathrm{BC})^{2}=(\mathrm{AC})^{2} \\
& (\mathrm{AO}-\mathrm{BO})^{2}+(\mathrm{BC})^{2}=(\mathrm{AC})^{2}
\end{aligned}
$$

where $\mathrm{AC}=\mathrm{AO}=\mathrm{R}$ (Radius of curvature of the plano convex lens)

In our case $\mathrm{R}=0.7 \mathrm{~m}$

$$
(\mathrm{R}-\mathrm{BO})^{2}+(\mathrm{BC})^{2}=(\mathrm{R})^{2}
$$

$$
(0.7-\mathrm{BO})^{2}=(\mathrm{R})^{2}-(\mathrm{BC})^{2}=(0.7)^{2}-\left(0.155 \times 10^{-2}\right)^{2}
$$

On simplification

$$
\mathrm{BO}=1.71 \times 10^{-6} \mathrm{~m}
$$

This result is in agreement with result obtained in section $1\left(1.76 \times 10^{-2} \mathrm{~m}\right)$. 


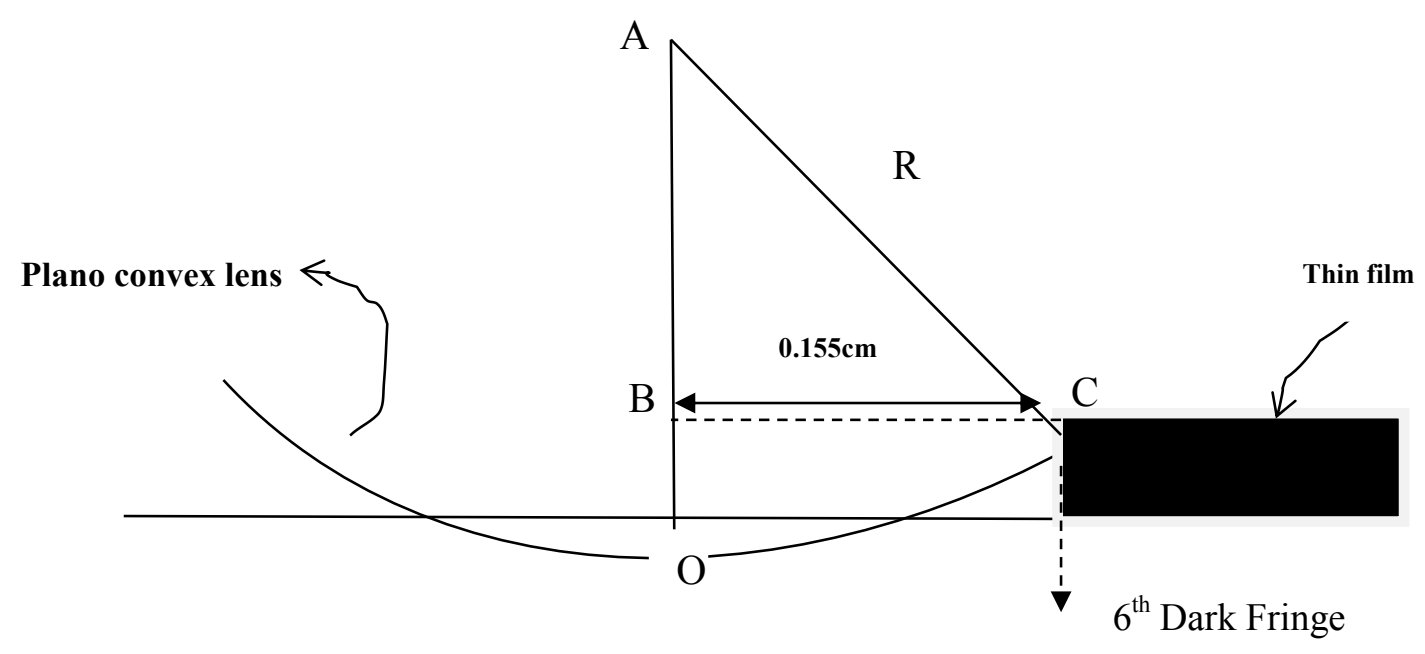

Fig. 2. Geometry of a plano convex lens kept on a plane glass plate with a thin film inserted in the air gap between lens and the glass plate.

\section{Section 3: Improvisation of Interference at Air wedge technique}

The method described in this paper can also be applied to improvise Interference at air wedge method which is conventionally performed to determine the thickness of thin films. It is based on the fact that that the thickness of a thin film in an air wedge is equal to the corresponding thickness of the air film adjacent to the thin film. By knowing the fringe number for the bright or dark fringe adjacent to the thin film, its thickness can be calculated easily by using the condition for constructive (bright fringe) or destructive interference (dark fringe).
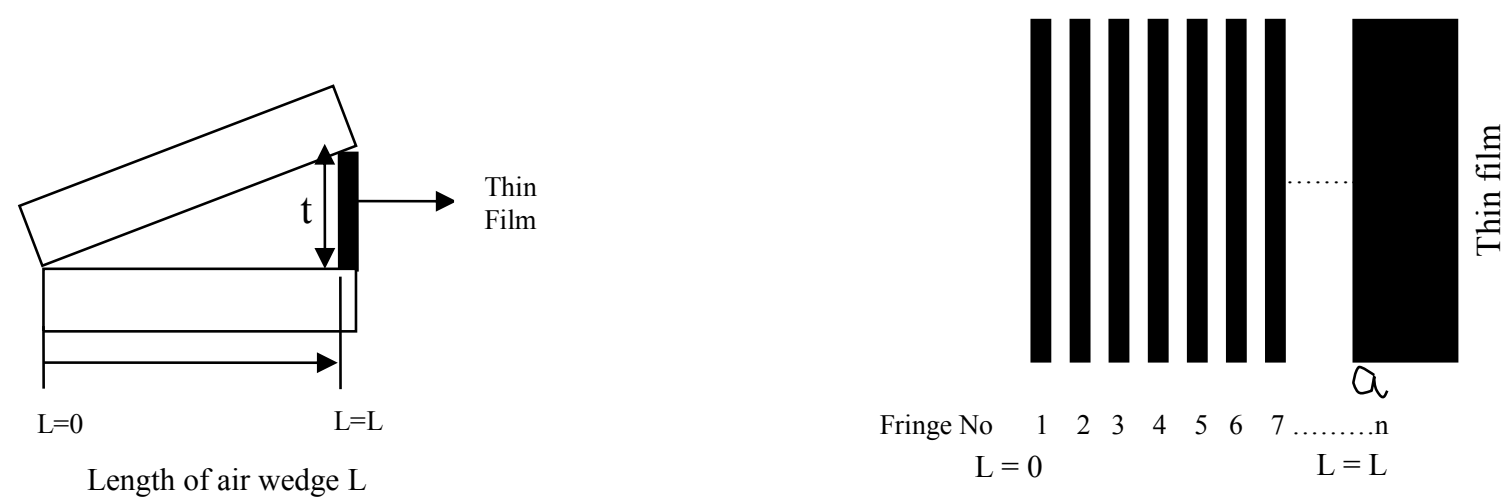

Fig. 3. A thin film of thickness ' $t$ ' at one end of the air wedge of length ' $L$ ' is shown .The straight fringes are of equal width and intensity are also shown.

The formation of a bright or dark fringe at a point is determined by the thickness of the air film at that point. If a dark fringe is formed next to the thin film in the wedge, then the 
thickness of the thin film (or the thickness of the air film) is given by the condition for destructive interference

$$
2 \mathrm{t}+\lambda / 2=(2 \mathrm{n}+1) \lambda / 2
$$

where $\mathrm{n}$ is the fringe number for the fringe next to thin film (at a in the figure above) i,e. $\mathrm{n}$ represents the number of fringes in the air wedge from $\mathrm{L}=0$ to $\mathrm{L}=\mathrm{L}$.

\section{a. For a carbon paper strip:}

When a carbon paper strip is used with Sodium Light $(\lambda=5893 \AA)$ the number of fringes in the air wedge from $\mathrm{L}=0$ to $\mathrm{L}=4 \mathrm{~cm}$ (the length of the air wedge) was 191 and it was dark fringe next to the carbon paper strip.

So

The condition for destructive interference is

$$
2 \mathrm{t}+\lambda / 2=(2 \mathrm{n}+1) \lambda / 2
$$

Here $\mathrm{n}=191$

$$
\lambda=5893 \times 10^{-10} m
$$

On substitution

$$
\begin{aligned}
& 2 \mathrm{t}=(2 \mathrm{n}+1) \lambda / 2-\lambda / 2=2 \mathrm{n} \lambda / 2=2 \times 191 \times 5893 \times 10^{-10} / 2=112 \times 10^{-6} \mathrm{~m}=112 \mu \mathrm{m} \\
& \mathrm{t}=56 \mu \mathrm{m}
\end{aligned}
$$

\section{b. For an ordinary paper:}

When a carbon paper strip is used with Sodium Light $(\lambda=5893 \AA)$ the number of fringes in the air wedge from $\mathrm{L}=0$ to $\mathrm{L}=4 \mathrm{~cm}$ (the length of the air wedge) was 209 and it was dark fringe next to the carbon paper strip.

So

The condition for destructive interference is

$$
2 \mathrm{t}+\lambda / 2=(2 \mathrm{n}+1) \lambda / 2
$$

Here $\mathrm{n}=209$

$\lambda=5893 \times 10^{-10} m$

On substitution

$$
\begin{aligned}
& 2 \mathrm{t}=(2 \mathrm{n}+1) \lambda / 2-\lambda / 2=2 \mathrm{n} \lambda / 2=2 \times 209 \times 5893 \times 10^{-10} / 2=123 \times 10^{-6} \mathrm{~m}=123 \mu \mathrm{m} \\
& \mathrm{t}=61.5 \mu \mathrm{m}
\end{aligned}
$$


The results show that this experiment can be a suitable method to determine the thickness of thin films. We suggest that this method is simpler than the conventional method practiced in the laboratories which is time consuming.

\section{CONCLUSIONS}

The method to find the thickness of thin films using Newton's rings set up is presented. The results are in agreement with the values found from geometrical method. We suggest that this method is simpler. An improvisation method to simplify the technique of finding thickness of thin films through Interference at Air wedge apparatus is also suggested.

\section{References}

[1] Handbook of Optics, Volume III, $2^{\text {nd }}$ Edition, (1995).

[2] Handbook of Optics, Bass, Sponsored by Optical Society of America, (2001).

[3] Introduction to Optics, Ajoy Ghatak, (1996). Tata Mcgraw-hill publn.

[4] Optics by Khandelwal, (1998). Himalya Publishers.

[5] Optics by Brijlal \& Subramanyam, (1992). S. Chand \& Company Publn.

[6] Optics by Eugene Hecht, $4^{\text {th }}$ edition, (2003). Addison \& Wesley Publn.

[7] Principles of Optics by M Born \& Wolf, (1990). Pergamn Press.

[8] Zdzisław Pluta, Tadeusz Hryniewicz, International Letters of Chemistry, Physics and Astronomy 2 (2012) 28-34.

[9] Zdzisław Pluta, Tadeusz Hryniewicz, International Letters of Chemistry, Physics and Astronomy 3 (2012) 1-10.

[10] Zdzisław Pluta, Tadeusz Hryniewicz, International Letters of Chemistry, Physics and Astronomy 3 (2012) 11-23.

[11] Zdzisław Pluta, Tadeusz Hryniewicz, International Letters of Chemistry, Physics and Astronomy 4 (2012) 1-7.

[12] Nadir Fadhil Habubi, et al., International Letters of Chemistry, Physics and Astronomy 4 (2013) 1-8.

[13] Saad F. Oboudi, Nadir F. Habubi, Ghuson H. Mohamed, Sami S. Chiad, International Letters of Chemistry, Physics and Astronomy 8(1) (2013) 78-86.

[14] Zdzisław Pluta, Tadeusz Hryniewicz, International Letters of Chemistry, Physics and Astronomy 8(2) (2013) 113-122.

[15] Sujan Kumar Das, et al., International Letters of Chemistry, Physics and Astronomy 10(1) (2013) 90-101. 


\section{Biography}

\section{Raveesha K. H.}

Faculty

Department of Physics

CMR Institute of Technology

IT Park Road

Kundalahalli

Bangalore-37

Karnataka state

India

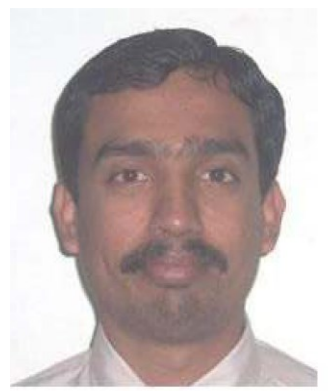

Raveesha K. H. has been teaching Physics and Electromagnetics courses for Engineering students from the past 16 years. I am currently involved with designing lab experiments for undergraduate students. I am pursuing research in the field of Radio Astronomy at Bangalore University and at Indian Institute of Astrophysics, Bangalore. My interests include designing astronomy related experiments.

\section{Dr Vijayakumar H. Doddamani}

Associate Professor

Department of Physics

Bangalore University

Jnanabharathi Campus

Off Mysore Road

Bangalore-56

Karnataka state

India

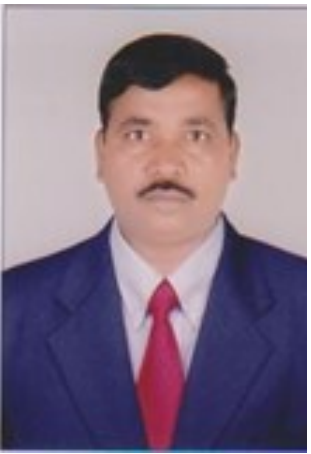

Dr. V. H. Doddamani has been teaching post graduate and doctoral students from the past 25 years. My research areas include Active Galactic Nuclei, Radio Astronomy, Plasma Physics etc. Currently, I am involved in designing radio-astronomy related experiments. 